\title{
DOI: 10.7596/taksad.v9i1.2422
}

Citation: Guralnyk, N., Zaitseva, A., \& Rastrygina, A. (2020). The Training of Music Teachers According to Humanistic Oriented Artistic Paradigm. Journal of History Culture and Art Research, 9(1), $249-257$. doi:http://dx.doi.org/10.7596/taksad.v9i1.2422

\section{The Training of Music Teachers According to Humanistic Oriented Artistic Paradigm}

\author{
Nataliia Guralnyk $^{1}$, Alla Zaitseva ${ }^{2}$, Alla Rastrygina ${ }^{3}$
}

\begin{abstract}
Radical changes in educational policy require the enhancing of educational systems quality and aiming at humanistic values. In this context, problems related to the forming of creative, competitive, existentially free and at the same time responsible citizens of Ukraine, capable of cultural identification and having respect for the "Other's" culture, get highly actualized. The article addresses the problem of improving the quality of training of specialists in the field of art in higher education, as a derivative of culture, in the context of a humanistic-oriented artistic paradigm. The introduction of the humanistic-oriented paradigm in art education has a dramatically innovative character, focusing future music teachers on the mobility and variability in the selection of forms and methods of artistic communication, and focuses on the subjective position of participants in the interaction with art. The accordance with international educational standards necessitates a holistic approach to the artistic and educational process need to prepare a competitive specialist. The article suggests the methods of theoretical analysis and generalization, which made it possible to formulate the investigated definition, which should be noted that a personality's culture is characterized not only by the ability for direct dialogue with art but also by "communication on the point of works of art". The phenomenology of communication in the artistic and educational projection is highlighted and the basic methodological guidelines for the formation are outlined. Particular attention is given on the outlining substantiating of an existential-reflective strategy of artistic and pedagogical communication of subjects of interaction with art in the context of a humanistic-oriented artistic paradigm.
\end{abstract}

Keywords: Musical pedagogical activities, Humanistic-orientation, Interpersonal relations, Artistic communication, Music teacher.

\footnotetext{
${ }^{1}$ Doctor of Pedagogical Sciences, Full Professor of the department of pedagogy of art and piano performance Faculty of Arts named after Anatoly Avdievsky National Pedagogical University named by M. Dragomanov, Kiev, Ukraine.

${ }^{2}$ Doctor of Pedagogical Sciences, Professor of the department of pedagogy of art and piano performance Faculty of Arts named after Anatoly Avdievsky National Pedagogical University named by M. Dragomanov, Kiev, Ukraine.

${ }^{3}$ Doctor of Pedagogical Science, Full Professor, Head of the Department of vocal-choral disciplines and methods of musical education, Volodymyr Vynnychenko Central Ukrainian State Pedagogical University, Kropyvnytskyi, Ukraine.
} 


\section{Introduction}

Radical changes in educational policy require the enhancing of educational systems quality, aiming at humanistic values, and the becoming of a teacher's personality and communicative culture. Higher education, as a derivative of culture, has at all times remained the source of cultural traditions and the center, where the people's spirituality develops. Therefore, the priority directions of reforming the national system of education in general and higher education in particular, the main substantive characteristics of which are fundamentalization, democratic principles, and humanistic orientation (Law of Ukraine, 2018).

In the center of personality-oriented education, in accordance with contemporary sociocultural requirements, is the education of a person capable of accepting values of cultural dialogue at the level of personal meanings. The social need to prepare a competitive specialist in accordance with international educational standards necessitates a holistic approach to the artistic and educational process.

The introduction of the humanistic oriented artistic paradigm in education has a dramatically innovative character, focusing future music teachers on the mobility and variability in the selection of forms and methods of artistic communication, and focuses on the subjective position of participants in the interaction with art. Unlike cognitive-informative (knowledge-enlightening paradigm, centered on intellectual (cognitive) personality development), the humanistic oriented artistic paradigm defines principled methodological orientations, places new accents on the priorities of the artistic and educational process, forms subjective, artistic, and communicative experience.

The need for comprehensive implementation of modern paradigmatic strategies is associated with finding the best ways to establish such relationships in the space of artistic dialogue, through which the student accepts cultural patterns of activity and behavior in the process of artistic communication. At the same time, the involvement of the concept of artistic and aesthetic dialogue in the absence of changes in the content and forms of artistic and educational activities of the future teacher of artistic disciplines (priority of co-creation, cooperation, the formation of artistic and communicative culture, etc.) leads to the declaration of these processes in practice.

In this context, problems related to the forming of creative, competitive, existentially free and at the same time responsible citizens of Ukraine, capable of cultural identification and having respect for the "Other's" culture, get highly actualized.

\section{Formulation of the problem}

It should be noted that a personality's culture is characterized not only by the ability for direct dialogue with art but also by "communication on the point of works of art," that is, the interpersonal communication between the subjects of artistic activity, which deals with artistic values, particular artists, their creativity, tastes, preferences, interests, etc. Active and holistic perception of music is based on empathy for the author's vision of the world, on personal creative comprehension, evaluation, and interpretation of the figurative content of the work, emotional fascination by intonation images that influence the activity of musical-sensory systems and the mode of functioning of cognitive processes. The pursuit of "objectification" of a personality's meaning through its coordination with the value-semantic field of the composer's work develops the need for discussing the artistic impressions, forms the ability of aesthetic judgment about a work of art, stimulates cognition of one's personal self and other people, and thus, it produces a strong effect on the becoming of intellectual, emotional, and behavioral spheres of a personality. 
In theory and practice of education, considerable experience has been accumulated, which determines the promising avenues for the theoretical rethinking of the training of future specialists in the field of art education. Scientific ideas of the theory of national education are considered in the works of the concepts of classical philosophy, psychology, pedagogy related to the communicative essence of art and the nature of artistic creativity, the understanding of artistic activities, and interrelations as communication are highlighted in the studies. In the field of musical and pedagogical education, there is a recent interest in the artistic and communicative content of the future music teachers training regarding the theoretical concepts of the forming of the artistic and pedagogical communication culture of a music teacher (Oleksiuk, O., Tkach, M. \& Lisun, D., 2013).

Artistry in the context of the definition of "communicative culture" of a future music teacher, in our understanding, is the quality that ensures the mutual experience of artistic images, includes emotional and aesthetic identification with the artistic world of a musical work in the process of its perception, cognition, evaluation, and creation (Zaitseva, 2015). Accordingly, "music school... functions in the interpersonal communication" (Guralnyk, 2007, p.375) and it displays the subject's culture in the structure of music and pedagogic communicative (Guralnyk, 2004, pp.18-22).

We think, that a progressive idea can be argued that "each person has their own unique individual sense context, which defines the comprehension of the artistic work. The difference between contexts in subjects of the pedagogical process does not destroy their communication while working on texts. On the contrary, an appeal to the teacher's spiritual experience, to their individual sense context, predetermines student's better understanding of the text of the artistic work. The most important factors in the interaction of the sense contexts of the student and the teacher are: Inclusion of the "third element" in the process of understanding the artwork" (Oleksiuk, Rebrova, \& Mikulinska, 2019, pp.104).

A. Rastrygina thinks that the "model under consideration, of the students of art faculties is one of the leading tasks of the functioning of professional art education in the context of the latest educational paradigm" (Rastrygina, 2018). Author understand that the artistic and educational space of the university is "just the spiritual and cultural environment, where a personality does not only recognize the peculiarities of local, national, European and world cultures by means of various types of art but also begins to realize his own identity and opportunities for the development of personal spiritual and creative potential" (Rastrygina, 2018).

Basing on philosophical concepts of M. Bakhtin, M. Buber, M. Kagan, we consider the artistic communication of a teacher and a student with the music as a special way of their spiritual unity in the process of comprehending art. It should be noted that such a method of interaction in the process of artistic communication presupposes a tendency towards the alignment of their psychological positions. The principle of equality is realized through: "specificity" and "incompleteness" of each subject of interaction since everyone has the right to come to the truth in his own way. It follows that in the process of artistic communication, in which all personality's properties of the involved subjects manifest themselves, their intellectual and emotional enrichment takes place; "artistic cognition necessarily implies taking into account peculiarities of the inner world of each subject of interaction, respect for his or her opinion as an interlocutor and communication partner, that is, an attitude towards multidimensional model" (Zaitseva, 2017, pp.75-78).

Taking into consideration basic provisions of the methodological approaches to the development of modern art education; the humanistic tendency in art comprehension; consideration of national foundations of artistic development of a personality; actualization of a personality's individualized approach to artistic education; introducing the poly-artistic context of professional art education; ensuring the appropriateness of culture and learning and observing the optimal balance 
between cognitive, evaluative and creative areas of educational activity, we consider the essence of artistic and communicative culture of a future music teacher in terms of systematic, synergistic, acmeological, personality-oriented, cultural, axiological approaches. The system of each of the stated approaches summarizes the main sources of philosophical knowledge, the content of which guides the awareness of the problems of shaping the artistic and communicative culture of a future music teacher, namely:

- Considering the internal resources of a teacher's and a student's personalities and possibilities of influencing them by the external artistic environment based on a synergistic approach, in the process of education; this approach also implies the actualization of the principles of activity, multidimensionality, independence, initiative, creativity, when the participants of the process of education and upbringing take part as open self-adjusting, selfdetermining systems.

- Assisting in the subject-to-subject creative interaction of a teacher and a student on the basis of a personality-centered approach.

- Determining of objective and subjective factors that facilitate or, on the contrary, impede the achievement of the heights of professional development based on the acmeological approach.

- Mastering the value aspects of the culture of artistic communication based on the axiological approach.

- Achieving the cultural conformity of musical and pedagogical training based on the cultural approach.

Systematization of methodological foundations of the study has led to the development of an existential-reflexive approach, which serves as the theoretical basis for the forming of artistic and communicative culture of a future teacher of musical art (Zaitseva, 2015, pp.155-163).

The forming of conceptual foundations of the mentioned approach has been promoted by the idea of "existential" communication in humanistic philosophy (K. Jaspers, M. Buber), modern theories of humanistic psychology (K. Rogers, A. Lengle), the leading positions of modern existential pedagogy representatives (J. Kneller, K. Gould, E. Breizach (USA), V. Barrett (Great Britain), M. Marcel (France), T. Morita (Japan), A. Fallico (Italy); theoretical and methodical concepts of artistic education (N. Guralnik, A. Kozyr, O. Myhaylychenko, V. Orlov, O. Oleksyuk, G. Padalka, A. Rastrygina, O. Rostovsky, O. Rudnitskaya, O. Hizhnaya, V. Shulgina, O. Scholokova, D. Yunik, and others).

The existential-reflexive approach we have developed is a system of scientific and pedagogical regulations that help to ensure artistic and creative interaction of a teacher and a student based on actualization, developing and deepening of such relations in the space of artistic dialogue, where the principles of mutual value, mutual respect, and cooperation are most fully realized. The existential-reflexive strategy of music training involves reliance on the value aspects of training interaction and allows a teacher to focus not only on his or her own feelings but also to include a personality's significant experiences of a student in the process of artistic communication. The effectiveness of music training in this context is achieved due to a student's awareness of his own feelings as to the things in art that are significant for his personality, as well as his tolerant attitude to the artistic experience of "the other". The implementation of the existential-reflexive approach implies the observance of certain principles of the forming of artistic and communicative culture of a future music teacher, which determine the search for new directions in solving the problem being studied, namely: 
- The principle of providing opportunities for teachers and students of an alternative choice of artistic and communicative behavioral strategies;

- The principle of achieving harmony of intellectual and emotional "background" of interaction.

- The principle of actualization of the dialectical unity of the ethical and aesthetic dimensions while the students are mastering art.

- The principle of aiming at values of the "dialogue of cultures".

- The principle of identity of goal setting of artistic and communicative actions of a teacher and a student.

Let's consider each of them in more details:

The principle of providing teachers and students with an alternative choice of artistic and communicative behavioral strategies lays in aiding a future music teacher towards an independent choice of artistic and communicative strategies from among several alternatives, that is, in giving him or her certain freedom of conscious choice of goals, content, forms, methods, means of organizing the artistic communication with a student, and a personality's responsibility for this process.

The implementation of this principle is connected with the student's ability to choose the optimal communicative style of activity depending on the specific situation of the artistic and educational process.

The principle of achieving harmony of intellectual and emotional "background" serves as a means of humanizing and harmonizing the relationship between the subjects of interaction, and expresses the need for rational comprehension and intuitively irrational "deepening" in the valuerelated and notion-related experiences that are forming "here and now" in the process of communication with art. This principle requires a teacher's ability to identify personal emotions, to monitor a student's emotions, to experience consonant feelings together with a student;

The principle of actualization of the dialectical unity of ethical and aesthetic principles in the students' mastering of art is the priority of ethical and aesthetic determination of the process of artistic communication. The substantive implementation of this principle is specified in the requirement for systematic and consistent pedagogical actions in the implementation of tolerant communicative behavioral strategies in the process of solving artistic and pedagogical tasks (taking into account the organic unity of a student's psyche, his or her musical abilities, musical background, and the general level of culture), and their amendments depending on the situation in the art education process;

The principle of aiming at values of the "dialogue of cultures" is reflected in the polyphony of culture and personality consciousness of the subjects of the art education process (their attitudes, values, notions). The implementation of this principle expresses the need to ensure an equal partnership of the subjects of interaction with art.

The implementation of the principle of identity of goal setting in artistic and communicative actions of a teacher and a student assumes systematic nature of their "resonant meetings" on the basis of comprehending the art in art educational and music performance activities; the gradual development of their creative artistic and communicative ties based on the step-by-step expansion of the "field" of artistic communication. The specificity of implementation of this principle is in the psychological readiness of a teacher to act simultaneously as the subject of creative interaction and 
to retain the meta-position in this process (to be the external regulator of artistic and communicative actions).

Next authors lean on the idea that contemporary higher artistic education is increasingly involved in the process of implementing the conceptions of lifelong learning, which has long been recognized in the European community and has effective practical experience in Ukraine. It radically changes the vector of the contemporary period of modernizing the educational system in higher artistic educational institutions. In particular, the theme of the sense of educational activity is actualized, that is some traditional metaphysical questions that require and imply understanding are raised (Oleksiuk, Rebrova, \& Mikulinska, 2019, p.101).

With regard to these principles, we have developed and experimentally introduced a methodical system for the forming of artistic and communicative culture of a future music teacher, defined the pedagogical conditions, methods, techniques, means, and forms of organizing the artistic and communicative activities of students in the process of musical education (Zaitseva, 2015).

\section{Methods}

The organization and content of the experimental step-by-step methodology, which took place in four stages, was carried out taking into account:

- humanistic orientation of students' communicative preparation;

- orientation to the "communication/dialogue" strategy of interaction between the subjects of the art-educational process;

- taking into account the specific communication on the basis of art, personal qualities and subject communication experience of each student;

- the application of innovative pedagogical technologies in the process of artistic communication.

The following forms of work were used in the organization of students' work: lectures, laboratory-practical, training sessions (use of special course elements), attendance of master classes, variant forms of individual practical classes with a teacher in the main instrument class; imitationgame forms of interaction, a direct acquaintance of students with the real educational process (attending schools, meetings with graduates who have success in the profession, etc.).

Particular attention was paid to the actualization of the reflexive component of interactive learning technology, educational interaction in the form of dialogue. Methods were introduced: "step-by-step facilitation of the interaction process", a discussion like "brainstorming", imitation and game technologies.

At this stage, such pedagogical techniques were used as: verbalization of feelings, arising from the perception of artistic image, use of polemical means of organizing artistic communication with the student, "introjections" ("reflection" by the teacher of student actions), etc.

The purpose of the simulated role-playing games introduced at this stage was to develop students' ability to plan and implement their own artistic and communicative activities from a cultural subject position. The role-playing games used at this stage involved the development of new forms of student behavior, awareness of their own inappropriate behavioral stereotypes of communication, and the creation of new strategies for artistic and creative interaction. 
In the course of playing activities, conditions were created for the student to verbalize his own feelings. The main strategy of the teacher was to focus on the conscious actions of the student. The teacher played (reflected) each action of the student, using verbal and non-verbal means (intonation, look, facial expressions, gestures, etc.), taking into account the individual characteristics of each student. The priority in the work of the teacher was to stimulate the ability of the participants of the game to reflexively analyze their own artistic and communicative activity, to predict its results; to stimulate students' motivational orientation to establish emotional and psychological contact with students.

It should be noted that in the process of imitation and playing activity we paid considerable attention to creating comfortable conditions for openness to our own experiences of subjects of artistic communication; preparation of teaching materials; a clear definition of artistic and communicative tasks.

An important component of the pedagogical activity, as well as in the acting profession, is a reflection - the teacher's ability to see "from aside" how his students perceive and appreciate awareness of their mental state. This is necessary in order to bring planning and real-life education into line. The teacher must have skills of professional self-awareness, which will help him feel his own "I" in the process of interaction with the class. Pedagogical artistry manifests itself in the variety and frequency of reflexive actions (Bulatova, 2001, p.56). The longest period in teaching an actor is not the history of art or stage language and dance, but the ability to communicate with a partner on stage. Not presence, but complicity; not just giving a replica, but organic coexistence in the scenic space, the ability to say and hear. Many students are indifferent to occupations in most cases, precisely because the erudite manager, concentrating on the problem of knowledge, almost completely ignores the form and method of their presentation, thereby not allowing students to express their thoughts, meet the level of the teacher, or even surpass it. Without such a "surplus", development is hardly possible. Only to be a teacher and a psychologist is not enough for a pedagogue. He must be able, if necessary, to be an actor, a creator, and the director of his own lesson (Bulatova, 2001, p.65).

Facilitating support of the teacher was aimed at gradual mastering of basic communicative competences, gaining experience of artistic and cultural context, minimizing possible problems in the process of establishing interaction with students.

In the process of discussion "like brainstorming", there were effective methods of stimulating students to express without fear of false answers; methods of creating a situation of success of interaction and so on.

It should be noted that we used the method of discussion "like brainstorming" in different forms of training: seminars, training, lectures, practical individual and group classes. Communicative reflection of the results of their own artistic and communicative activity allowed students to identify the existing problems of communication on the basis of art, possible ways of their constructive solution, to determine the criteria for selecting the best methods for the implementation of the tasks.

Increasing the level of students' motivation to establish productive interaction with students was facilitated by a set of communicative tasks for the verbalization of knowledge and feelings that arose in the process of artistic multilateral communication. Discussion of a particular artistic and communicative situation was predicted, modeled by the teacher, but was not prepared in advance to prevent the loss of the meaning of "live" dialogue as free communication of two equal "consciousnesses" in the artistic and aesthetic field of culture. 
The skill of the teacher involved the ability to create a situation of searching for artistic truth, taking into account students' reactions to the meanings, values of a particular situation of artistic communication, arising "here and now" in the lesson.

Dialogue form of artistic communication between the teacher and the student in the process of individual lessons in the profession involved the use of techniques such as: the reception of incompleteness of the dialogue, which reveals the problematic level of its content; the reception of decentralization and decentralization, reflecting the possible transition from one's own point of view as the only true one.

Thus, the application of the specified forms and methods of work aimed at the accumulation of students with some practical experience of playing, living artistic and communicative situations "here and now", fixed in the minds of students a constant of tolerance, which facilitated the formation of their psychological readiness for culturally appropriate interaction with the student.

Students acquire skills in various fields of communication: artistic and interpersonal. The general artistic and communicative field of the lesson in the context of realization of the specified forms and methods was the basis for expressing the feelings of the subjects of interaction, the polyphony of their thoughts regarding the interpretation and evaluation of a particular work of art, the situation in the lesson, etc.

Performing communicative exercises, role-playing games of communicative direction helped to increase the level of students' motivational orientation to establish emotional and psychological contact with students, there was a reflexive awareness of the importance of such spiritual and personality qualities as: empathy, congruence, emotional flexibility, enrichment of their "artistic thesaurus", sensory experience, development of empathic abilities.

The use of communication exercises, imitation-role-playing, dialog-discussion technologies, methods of sensation verbalization, introjection made it possible to "live" by students real artistic and communicative situations "here and now", facilitated the activation of their reflexive processes of understanding themselves and others. The repeated reproduction of artistic and communicative situations, their reflective analysis, contributed to the transfer of acquired communicative competences to new situations of artistic and educational activity.

\section{Conclusion}

A systemic view on the nature of artistic communication of a future music teacher allows us to consider the specifics of this phenomenon from the spiritual and dialogical viewpoints, reflected in the subject-to-subject character of artistic communication of a teacher and a student, mediated by the spiritual "I" of the artistic image of a piece of music. In result of the theoretical generalization and realization of the acquired pedagogical experience, we came to the conclusion that the artistic and communicative culture of a future teacher of musical art should be regarded as an integrative quality that determines his or her ability to establish emotional and psychological contact with a student, to turn artistic and educational activities into a culture creative process, that determines the vector of his or her humanistic aspiration at the understanding, rethinking, and correcting the personal subjective development and realization in the process of communication with the art of a unique creative potential of a student's personality. The pedagogical management of this process involves the creation of such an emotional and notional core of the lesson that promotes joint creativity of the subjects of the artistic and educational process, the activity and coherence of their artistic positions, ensures the utmost emotional involvement in the common "semantic field" of the lesson. 
The results of the fulfilled study allow us to conclude that the artistic communicative culture performs the function of extrapolation, the specific projection of the spiritual culture of a future music teacher in the sphere of his artistic and communicative activities, allows to achieve a more conscious level of complicity, empathy, and mutual understanding with the other subject of interaction with art. It is positioned as the spiritual humanistic vector of aiming a future teacher of music at perceiving the student's individuality, at comprehending his or her worth, at giving them the right to retain their individual existence in the process of interaction with art. The holistic essence of the investigated integrative-personal quality is determined by the ability of a future music teacher to reflect on his own thoughts and feelings, to align psychological subjective (not status-related) standpoints with a student, to comply with high level of ethical requirements for his or her own behavior, alternative choice of artistic communicative strategies, the use of more complex psychological nuances of communicative strategies of artistic communication.

The process of specialists' training in the field of art education in the context of a humanistic oriented artistic paradigm is viewed in the consistent dialogization of consciousness and communication of a teacher and a student on the basis of:

- Harmonization of emotional and intellectual dominants in their relationship in the educational process;

- Engagement of creative projects and innovative technologies facilitating the systematic nature of creative relationships in educational, practical, and music performing activities.

\section{References}

Bulatova, O. S. (2001). Pedagogical activity: text-book for high pedagogical school students. Moscow: Academy.

Guralnyk, N. P. (2004). Culture in the structure of subjects attitude of music and pedagogic communicative: society, high school, piano class. Science and education, 30, 18-22. Dnipropetrovs`k: Science and education.

Guralnyk, N. P. (2007). Ukrayinska fortepianna shkola XX stolittia v konteksti musychnoi pedagogiky. Kyiv: NPU.

Law of Ukraine. (2018). Retrieved from: https://zakon.rada.gov.ua/laws.

Oleksiuk, O. M., Tkach, M. M., \& Lisun, D. V. (2013). Hermeneutic approach in higher artistic education: collective monograph. Kyiv: Kyiv B. Hrinchenko University.

Oleksiuk, O., Rebrova, O., \& Mikulinska, O. (2019). Dramatic Hermeneutics as a Perspective Technology in the Artistic Education. Journal of History Culture and Art Research, 8(3), 100-112. Retrieved from: http://dx.doi.org/10.7596/taksad.v8i3.2146

Rastrygina, A. (2018). Model dukhovnosti vospitaniya v obrazovatelnom paradigmalnom prostranstve globalizovannogo mira. Applied Research in Studies and Practice, 14, 80-87.

Zaitseva, A. (2015). Fundamental principles of forming of artistically-communicative culture of the future teacher music. European Journal of Scientific Research, 277-285.

Zaitseva, A. (2017). Artistic and communicative culture of the future teacher of music: theory, methodology, methodical aspects. Kyiv: NPU. 